\title{
TÁC ĐộNG CỦA ĐẠI DỊCH COVID-19 LÊN NGÀNH LOGISTICS Ở VIẸTT NAM
}

\author{
Nguyễn Ý Nhi, Lê Ngân Phương, Nguyễn Thu Phương, \\ Nguyễn Minh Quang, Ngô Việt Quân
}

Đại học Quốc gia Hà Nội

Ngày 05 tháng 02 năm 2022

Preprint DOI: 10.31219/osf.io/vamwy

\section{Tác động của đại dịch COVID-19 lên ngành Logistics ở Việt Nam \\ 1. Tác động đến doanh nghiệp}

\subsection{Tình hình}

Đại dịch COVID-19 tác động mạnh mẽ tới các nền kinh tế và đời sống xã hội của cả thế giới, làm đảo lộn chuỗi cung ứng toàn cầu, trong đó có hoạt động logistics (La, 2020).

Nhằm đánh giá mức độ ảnh hưởng của dịch COVID-19 đối với hoạt động của doanh nghiệp ngành Logistics, vừa qua, Hiệp hội Doanh nghiệp dịch vụ Logistics Việt Nam (VLA) đã tiến hành khảo sát, lấy ý kiến của các doanh nghiệp về những khó khăn, thiệt hại mà doanh nghiệp đang gặp phải. Kết quả khảo sát cho thấy, trong quý I/2020 có khoảng $15 \%$ doanh nghiệp bị giảm 50\% doanh thu so với năm 2019 và hơn $50 \%$ doanh nghiệp giảm số lượng dịch vụ Logistics trong nước và quốc tế từ $10 \%-30 \%$ so với cùng kỳ năm ngoái. Khoảng $97 \%$ doanh nghiệp kinh doanh dịch vụ Logistics là vừa và nhỏ nên bị tác động nặng nề. Từ tháng 5/2020, hoạt động logistics được phục hồi theo nền kinh tế nhưng hiện nay nhìn chung khoảng 20\% doanh nghiệp kinh doanh dịch 
vụ Logistics vẫn còn suy giảm về hoạt động. So với trước đại dịch, lượng hàng hóa vận tải qua biên giới giảm đi nhiều, phải đổi lái xe, đổi đầu kéo là những khó khăn hiện hữu.

Theo số liệu của tổng cục thống kê tháng 9/2020, cả nước có 10,3 nghìn doanh nghiệp thành lập mới với số vốn đăng ký là 203,3 nghìn tỷ đồng và số lao động đăng ký là 83 nghìn lao động, giảm 23,1\% về số doanh nghiệp, giảm 29,6\% về vốn đăng ký và giảm $13,8 \%$ về số lao động tháng trước. Trong tháng $9 / 2020$, số lượng doanh nghiệp vận tải kho bãi được thành lập mới giảm 5,3\% so với cùng kỳ năm ngoái (đạt 4.033 doanh nghiệp, thấp hơn mức giảm chung của tất cả các ngành). Từ đầu năm đến hết tháng 9/2020 cũng có 485 doanh nghiệp vận tải, kho bãi nước ta đã hoàn tất thủ tục giải thể (Bộ Công thương, 2020). Nhiều doanh nghiệp Logistics vừa và nhỏ nằm bên bờ vực phá sản; nhiều lao động bị giãn và mất việc nếu như đại dịch kéo dài thêm một thời gian nữa.

Bà Chu Thị Kiều Liên, Trưởng chi nhánh Hà Nội của công ty T\&M Forwarding (trụ sở chính tại TP. Hồ Chí Minh), một công ty chuyên vận chuyển hàng hóa quốc tế hai chiều đi Hoa Kỳ, Canada, Trung Quốc... cho biết so với cùng kỳ năm 2019, doanh thu đều giảm; so với kế hoạch 2020 thì đều giảm 20\%. Điều này chứng tỏ dịch COVID19 đã có ảnh hưởng tới hoạt động của công ty.

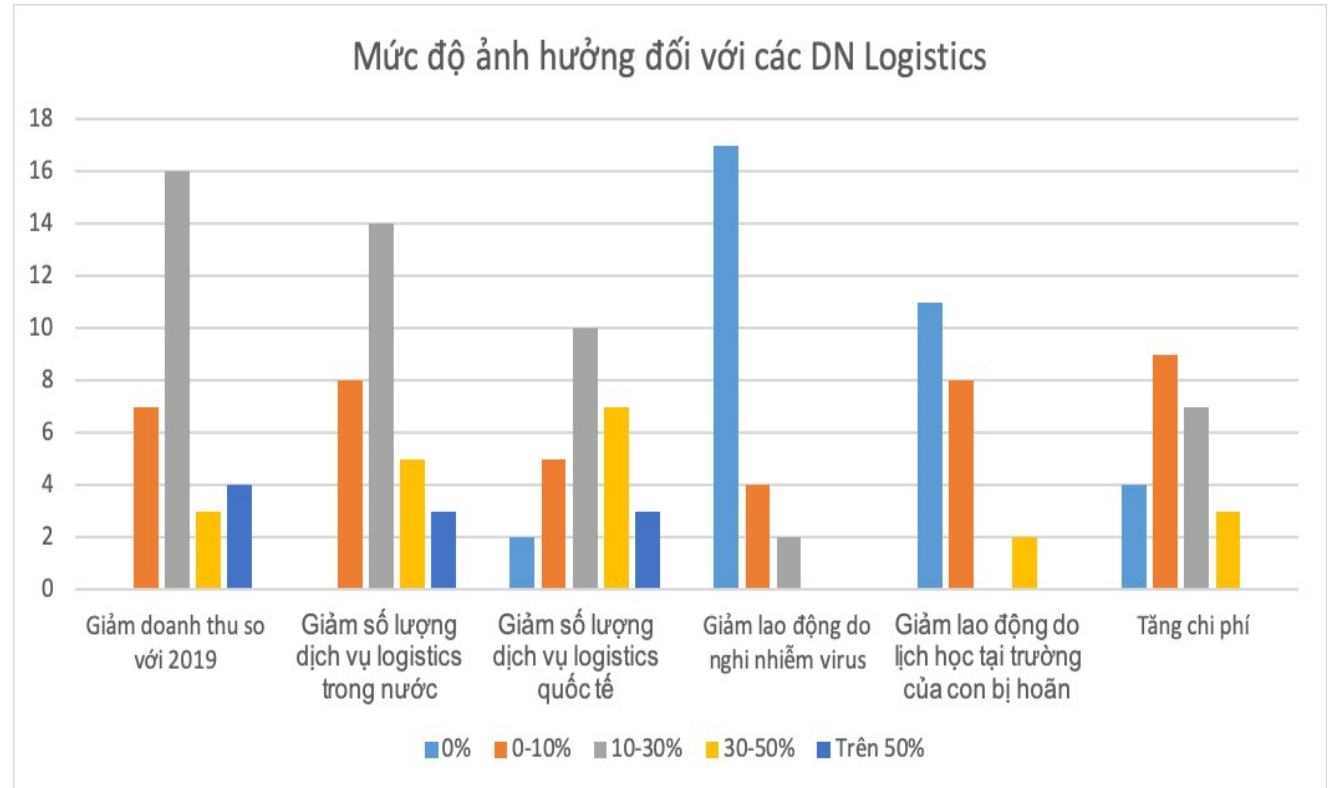

Hình 1. Mức độ ảnh hương của dịch COVID-19 đối với các doanh nghiệp Logistics Nguồn: Vietnam Logistics Review (Anh, 2020) 
Ngành dịch vụ Logistics Việt Nam cũng chịu tác động của khoảng hơn 30 doanh nghiệp cung cấp Logistics xuyên quốc gia có quan hệ mật thiết với các chủ hàng và hãng tàu biển lớn của thế giới. Nhu cầu quốc tế giảm sút dẫn đến việc đơn hàng xuất khẩu giảm, nhiều công ty phải cho công nhân nghỉ việc. Vì vậy, doanh nghiệp dịch vụ logistics bị tác động và ảnh hưởng theo. Đây là một đặc điểm nổi bật mà ngành dịch vụ Logistics thế giới và Việt Nam đã và đang chịu tác động.

\subsection{Nguyên nhân}

Nguyên nhân đầu tiên là nhiều nhà máy phải giảm hoạt động nên lượng hàng hóa cần lưu chuyển ít đi dẫn đến việc vận chuyển và giao nhận hàng hóa trong chuỗi cung ứng cũng giảm, ảnh hưởng lớn đến hoạt động của các doanh nghiệp kinh doanh dịch vụ vận tải Logistics. Bên cạnh đó, doanh nghiệp cũng bị giảm nguồn thu đáng kể đối với hàng hóa xuất khẩu, nhập khẩu từ các nước có dịch như Trung Quốc, Hàn Quốc, Nhật Bản, Singapore,... (Trọng, 2021)

Tiếp theo, trong tình hình dịch bệnh như hiện nay việc các doanh nghiệp thiếu hụt nguồn nguyên liệu để sản xuất và khó tìm đầu ra cho sản phẩm tại vực châu Á và một số khu vực khác, gây ra tình trạng sản xuất dư thừa, không xuất khẩu được.

Hơn nữa, theo một số doanh nghiệp Logistics, việc cơ quan quản lý nhà nước ban hành văn bản tính lại trị giá và truy thu thuế, việc tăng giá bốc xếp tại các cảng biển, cắt giảm, không mở các địa điểm thu phí sử dụng kết cấu hạ tầng tại khu vực cảng biển của địa phương... đã gây không ít khó khăn cho doanh nghiệp.

Bà Phạm Hạnh, Thư ký truyền thông của VLA cho biết, khó khăn lớn nhất mà các doanh nghiệp logistics phải đương đầu hiện nay là giải quyết vấn đề về thanh khoản tài chính và giải quyết việc làm cho người lao động, trong khi các hoạt động sản xuất, xuất nhập khẩu đều giảm sâu.

Ngoài ra, còn có một số vấn đề phát sinh khác như một số khách hàng Trung Quốc gặp khó khăn về tài chính dẫn đến mất khả năng trả nợ cho chủ hàng, nhà cung cấp Việt Nam kéo theo việc chủ hàng chậm thanh toán cho doanh nghiệp logistics. 


\section{Tác động đến dịch vụ vận tải}

Hoạt động dịch vụ vận tải chịu tác động nặng nề trong tình hình dịch bệnh, trước hết đặc biệt là vận tải hàng không, đường sắt và đường bộ. Theo "Báo cáo Thị trường Logistics Việt Nam 9 tháng đầu năm 2020" của Bộ Công thương: vận tải hàng hóa đạt $1.246,6$ triệu tấn hàng, giảm 7,3\% so với cùng kỳ năm trước, luân chuyển đạt 242,5 tỷ tấn.km, giảm $8,2 \%$ cùng kỳ năm trước.

\subsection{Dịch vụ vận tải đường bộ}

Vận tải hàng hóa bằng đường bộ ở Việt Nam đang là hình thức vận chuyển phổ biến nhất. Nó có những đóng góp to lớn trong việc lưu thông hàng hóa và dịch vụ tạo điều kiện cho giao thương phát triển. Tuy nhiên, trong tình hình dịch bệnh, dịch vụ vận tải đường bộ đang gặp phải những khó khăn nhất định. Cụ thể, khối lượng vận tải đường bộ qua biên giới giảm mạnh, phải cách ly lái xe để đảm bảo an toàn hay đổi lái xe, đổi xe đầu kéo đang là một trong những khó khăn lớn nhất. Vận tải trong nước gặp nhiều khó khăn do giãn cách xã hội theo chỉ thị của Thủ tướng Chính phủ. Hơn nữa, các tuyến biên giới đều khó kiếm được nhà cung cấp vận chuyển, lượng hàng giảm dẫn đến nhu cầu về vận tải đường bộ giảm. Theo thống kê, trong 9 tháng đầu năm 2020, vận tải hàng hóa đường bộ đạt 936,9 triệu tấn, giảm 7,4\% so với cùng kỳ năm trước; luân chuyển hàng hóa đường bộ đạt 65,2 tỷ tấn.km giảm 14,2\%. Có khoảng 50-60\% doanh nghiệp vận tải đường bộ giảm hoạt động và doanh thu trong thời gian đỉnh dịch. (Bộ Công thương, 2020)

Nhìn chung, do tác động của dịch COVID-19 nên dịch vụ vận tải đường bộ gặp không ít những khó khăn, đòi hỏi Chính phủ cũng như các doanh nghiệp cần có giải pháp khắc phục để giảm thiểu thiệt hại ở mức thấp nhất.

\subsection{Dịch vu vận tải đường biển và cảng biển}

Trong tình hình dịch bệnh, cụ thể là vào năm 2020 là năm nhiều khó khăn đối với dịch vụ vận tải đường biển bởi sự suy giảm trong hoạt động thương mại trên thế giới và ở Việt Nam. Tác động của COVID-19 đối với vận tải hàng hóa bằng đường biển và cảng biển trở nên rõ ràng hơn vào quý II/ 2020. Khó khăn với ngành vận tải đường biển và cảng biển trong nửa đầu năm 2020 không chỉ do khối lượng thương mại giảm mà còn 
bởi tình trạng thiếu nhân công và không thể đổi thủy thủ đoàn như thường lệ, bởi các quy định hạn chế và cách ly đối với người nhập khẩu tại các nước. Các yêu cầu về giao thức y tế mới trong bối cảnh dịch bệnh và ngay cả khi đã chuyển sang giai đoạn "bình thường mới” dẫn đến nhiều quy trình hơn tại các cảng biển, làm ảnh hưởng đến lộ trình chung của các đội tàu (BBT, 2020). Cùng với đó việc tiêm vắc xin cho các đối tượng liên quan đến hoạt động trên tàu biển, tại các cảng còn hạn chế. Tuy nhiên, so với các loại hình dịch vụ vận tải khác, dịch vụ vận tải biển ít bị tác động bởi dịch COVID-19 hơn và đạt được những tăng trưởng nhất định. Giá cước vận tải biển cao cùng sản lượng hàng hóa xuất nhập khẩu tăng mạnh khiến lợi nhuận của nhiều công ty Logistics kinh doanh dịch vụ vận tải biển tăng đột biến trong năm 2021, nhưng đồng thời cũng gây khó khăn và gánh nặng chi phí rất lớn cho các doanh nghiệp xuất nhập khẩu hàng hóa. Bên cạnh đó, khối lượng hàng hóa thông qua cảng biển tăng trưởng mạnh cũng giúp các công ty khai thác cảng đạt được lợi nhuận tích cực bất chấp khó khăn do dịch Covid-19 (Bộ Công thương, 2021).

Đơn vị: triệu tấn

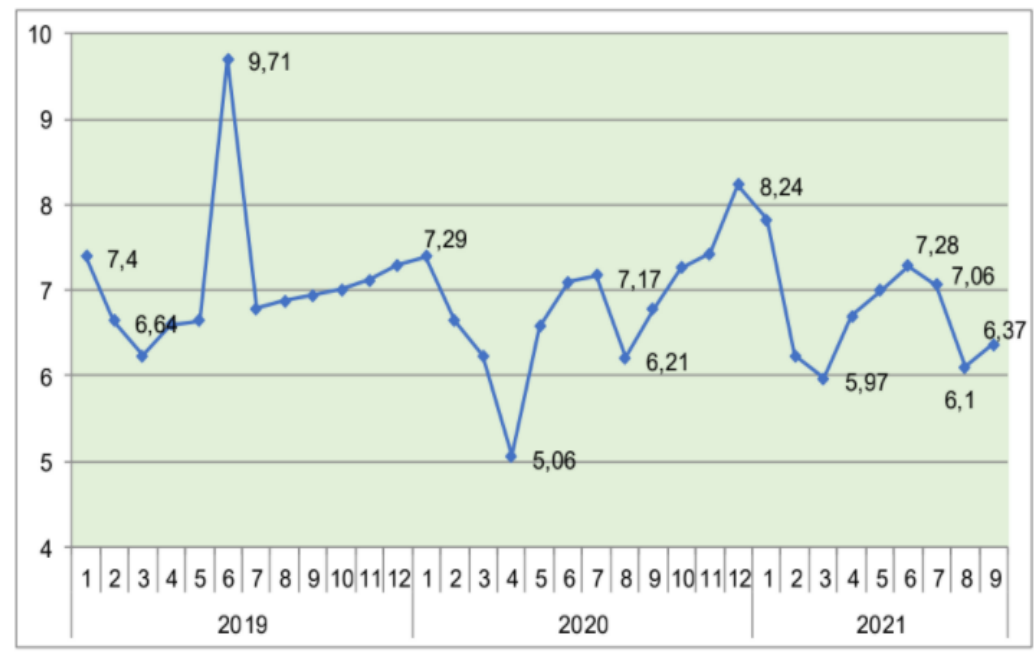

Nguốn: Tổng hợp từ số liệu của Tổng cục Thống kê

Hình 2. Vận tải hàng hóa bằng đường biển

Nguồn: Báo cáo Logistics Việt Nam 2021 - Bộ Công thuoong

\subsection{Dịch vụ vận tải đưòng hàng không}

Hàng không là một ngành có tầm quan trọng đặc biệt, không chỉ trong phát triển kinh tế, mà còn đối với các vấn đề an ninh, quân sự và chủ quyền quốc gia. Tuy nhiên, 
khi đại dịch COVID-19 bùng phát, nền kinh tế thế giới đã phải chịu nhiều thiệt hại to lớn, mà ngành đầu tiên chịu tác động nặng nề nhất chính là ngành vận tải hàng không trong đó có cả ngành vận tải hàng không Việt Nam. Trong tháng 9/2020 vận tải hàng hóa bằng đường hàng không chỉ đạt 17,6 nghìn tấn, giảm $12 \%$ so với tháng $8 / 2020$ và 56,2\% so với tháng 9/2019. 9 tháng năm 2020 đạt 196,6 nghìn tấn, giảm 39,4\% so với cùng kỳ năm 2019; luân chuyển hàng hóa đạt 2,6 tỷ tấn.km, giảm.54,2\% so với cùng kỳ năm 2019 (Bộ Công thương, 2020).

Đơn vị: nghìn tấn

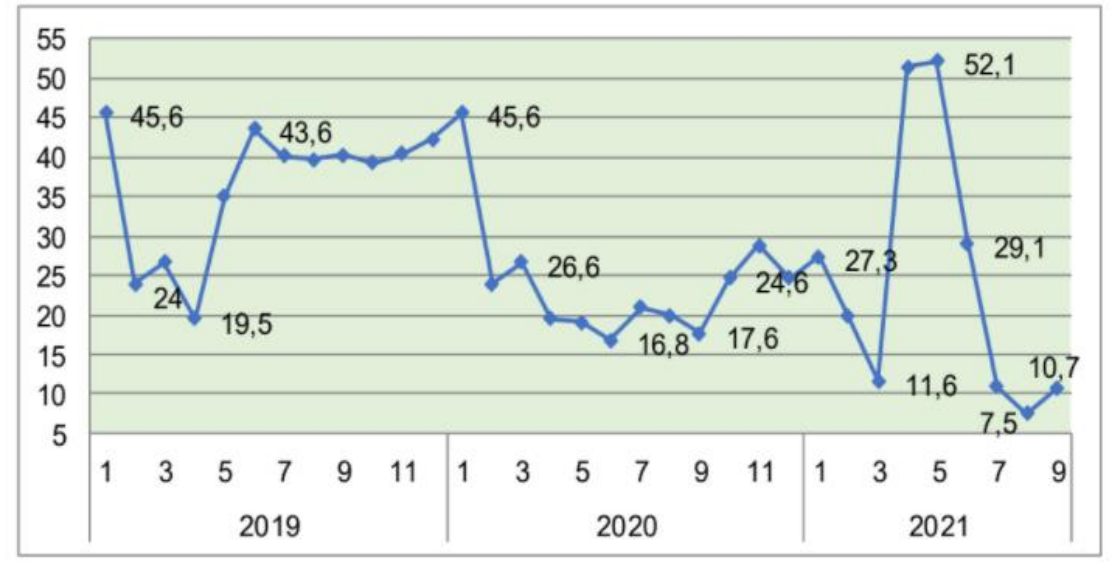

Nguôn: Tính toán từ số liệu của Tổng cục Thống kê

Hình 3. Vận tải hàng hóa bằng đường hàng không

Nguồn: Báo cáo Logistics Việt Nam 2021 - Bộ Công thưong

Như vậy, trong số các phương thức vận tải thì hàng không ghi nhận mức giảm mạnh nhất, do bị ảnh hưởng nặng nề nhất bởi các biện pháp hạn chế đi lại giữa các quốc gia trong bối cảnh dịch COVID-19 vẫn diễn biến phức tạp. Tuy nhiên, thời gian gần đây, cùng với sự hồi phục của khu vực châu Âu và Hoa Kỳ khi các nước mở cửa lại nền kinh tế cũng như khuyến khích du lịch, thương mại, ngành hàng không dự báo sẽ phục hồi từ cuối năm 2021 hoặc năm 2022. Vận chuyển hàng hóa các máy bay chở khách dự báo sẽ dần hồi phục sau thời gian đóng băng từ đầu năm 2020 đến nay. Ngoài ra, phân khúc vận chuyển hàng không cho hàng thương mại điện tử xuyên biên giới và hàng dược phẩm, đặc biệt là vắc-xin được dự báo sẽ có nhiều triển vọng nhất trong số các phân khúc vận tải hàng không (Bộ Công thương, 2021). 


\subsection{Dịch vụ vận tải đường sắt}

Dịch COVID-19 đã tác động, ảnh hưởng mạnh mẽ tới ngành dịch vụ vận tải đường sắt do lưu chuyển hành khách và hàng hóa bị giảm sâu. Về kho bãi, khó khăn lớn nhất là phần lớn các kho hàng tổng hợp đã xuống cấp, không có kho nào đạt tiêu chuẩn để lưu trữ, bảo quản các mặt hàng tươi sống, hàng hóa có giá trị cao. Cả hệ thống đường sắt Việt Nam chỉ có bốn ga có bãi hàng hóa và thiết bị xếp dỡ, bảo quản container. Tuy nhiên, trong khó khăn, dịch vụ Logistics đường sắt có những hoạt động mới trong vận tải liên vận quốc tế, góp phần cùng ngành thương mại chống dịch COVID-19 thành công trong việc vận chuyển hàng hóa có hiệu quả với Trung Quốc. Trong khi vận tải đường bộ đang bị dồn ứ tại cửa khẩu do công tác kiểm dịch bị siết chặt, khiến chi phí và thời gian đều bị đội lên thì đường sắt có lợi thế hơn hẳn. Tàu chở hàng có thể làm thủ tục thông quan rất nhanh, do công tác phòng dịch, kiểm dịch cho tài xế, nhân lực đi kèm đơn giản hơn hẳn so với đường bộ, nguy cơ lây nhiễm dịch thấp hơn. Hiện đường sắt đang là giải pháp tối ưu cho xuất khẩu hàng nông sản sang Trung Quốc. (Duy, 2020)

\section{Tác động đến dịch vụ giao nhận}

Các hoạt động Logistics như vận tải giảm do dịch vụ thông quan bị cản trở, dịch vụ kho bãi, cước cũng bị ảnh hưởng nặng. Cửa khẩu Trung Quốc vốn đã thường xuyên bị quá tải, nay do ảnh hưởng dịch nên phát sinh lưu xe, việc xuất nhập khẩu ở các cửa khẩu trở nên phức tạp và mất thời gian hơn. Từ đó, dẫn đến tình trạng hàng hóa dễ hư hỏng bị giảm chất lượng, lái xe không muốn bị rắc rối, chậm trễ nên thường từ chối vận chuyển, ảnh hưởng đến tiến độ giao hàng. Cũng theo VLA, các tuyến chủ yếu là từ Trung Quốc, Hàn Quốc, Nhật Bản, các hãng tàu như ONE, HMM và một số hãng tàu khác cũng đều giảm tàu nối tất cả các tuyến, điều này đã ảnh hưởng không nhỏ đến lịch xuất hàng và chất lượng dịch vụ. Hầu hết hàng nhập trên các tuyến về Việt Nam giảm mạnh, một số thị trường khác bị kiểm dịch gắt gao. Các thủ tục vận hành từ thị trường khu vực châu Á và một số khu vực khác chậm trễ hơn so với bình thường.

\section{Tác động đến hoạt động đào tạo nguồn nhân lực cho ngành Logistics ở Việt Nam}

Theo phân tích như trên cho thấy, đại dịch COVID-19 đã ảnh hưởng nặng nề đến toàn bộ thị trường lao động, đặc biệt lao động trong ngành Logistics. Nguy cơ phá sản 
hàng loạt của các doanh nghiệp hoạt động trong lĩnh vực Logistics cũng như sự gãy đổ, thay đổi và gián đoạn của các chuỗi cung ứng đã ảnh hưởng nặng nề đến cục diện của thị trường lao động (Ninh et al., 2020). Yêu cầu cấp bách trong việc ứng phó với sự lây lan của COVID-19 bằng biện pháp giãn cách xã hội tại hầu hết các nước trên thế giới đã buộc các cửa hàng bán lẻ, trung tâm thương mại phải đóng cửa, các hệ thống phân phối và chuỗi cung ứng Logistics bị giảm sản lượng, quy mô hoạt động cũng như thay đổi hình thức hoạt động đã dẫn đến việc hàng triệu lao động có nguy cơ bị mất việc đồng thời phát sinh nhiều kỹ năng mới từ người lao động để có thể giúp doanh nghiệp đáp ứng sự thay đổi theo hình thức và quy mô kinh doanh mới. Tuy nhiên, trên thực tế, trong khi các cơ sở giáo dục nghề nghiệp còn đang loay hoay với việc chuyển đổi và thích ứng với hình thức đào tạo mới, việc hợp tác với doanh nghiệp tạm thời bị gián đoạn dẫn đến việc nắm bắt nhu cầu về các kỹ năng, năng lực mới từ thị trường lao động rất hạn chế. Bên cạnh đó, một thách thức rất lớn mà các cơ sở giáo dục nghề nghiệp cũng như doanh nghiệp Logistics nói riêng và các doanh nghiệp nói chung đang phải đối mặt đó là xây dựng một chiến lược đào tạo, bồi dưỡng, bổ sung kỹ năng cho người lao động trong bối cảnh dịch bệnh nhằm đảm bảo an toàn sức khỏe cho cộng đồng nhưng đồng thời vẫn đáp ứng được việc cung cấp cho thị trường lao động những kỹ năng và năng lực thực hiện cần thiết để duy trì việc làm cho người lao động cũng như duy trì và phát triển hoạt động của doanh nghiệp. Điều này cần sự chung tay của tất cả các bên liên quan cũng như nỗ lực của cơ sở giáo dục nghề nghiệp và doanh nghiệp.

\section{Giải pháp}

Phương hướng tiếp cận để giải quyết vấn đề là dựa vào thông tin đầy đủ chính xác, đầu vào của hệ xử lý thông tin $3 \mathrm{D}$, trong đó lấy chuyên gia đầu ngành, sự hợp tác giữa các bên liên quan để tìm ra các giải pháp sáng tạo. Cách tiếp cận chuyên gia, đa ngành, hệ thống và cần được thực hiện kỷ luật trong thời gian đủ dài đến khi các nỗ lực có kết quả (Vuong, Q.H., 2022; Vuong \& Napier, 2014).

\section{Giải pháp của Chính phủ}

Quốc hội đã thông qua Nghị quyết về việc cắt giảm 30\% thuế thu nhập năm 2020 cho các doanh nghiệp có doanh thu dưới 200 tỷ đồng. Doanh nghiệp sẽ được hưởng lợi rất nhiều từ quyết định này bên cạnh các giải pháp hỗ trợ khác của Chính phủ cho doanh 
nghiệp kinh doanh Logistics trong sản xuất, kinh doanh, rà soát các loại thuế, phí, có các giải pháp hỗ trợ giảm chi phí về vận tải như giảm giá BOT, phí cầu đường, bến bãi, phí lưu giữ phương tiện,... Bên cạnh đó, Chính phủ cần cung cấp thông tin kịp thời, chính xác cho doanh nghiệp về tình hình dịch bệnh và kịch bản kinh tế của Chính phủ; cung cấp đầy đủ khẩu trang y tế cho doanh nghiệp nếu diễn biến tình hình dịch bệnh ngày càng trở nên phức tạp hơn. Ngoài ra, Chính phủ nên trao đổi them hoặc tổ chức các cuộc họp với các hãng vận tải, hãng tàu nhằm giảm giá về dịch vụ vận chuyển hàng hóa, giảm phí dịch vụ tại cảng để giảm bớt chi phí lưu thông hàng hóa, góp phần hỗ trợ cho doanh nghiệp sản xuất và doanh nghiệp Logistics; kiểm soát được giá, không tăng giá quá cao, đặc biệt là phí LSS, LSS .Đồng thời, các cơ quan có liên quan phải triển khai công tác đảm bảo chống dịch ở các cửa khẩu,cửa ngõ ra vào như: đường bộ, cảng biển theo hướng tạo điều kiện thuận lợi cho doanh nghiệp; phối hợp với các tỉnh biên giới phía Bắc bố trí lực lượng chức năng tổ chức phân luồng, phân tuyến tại đường bộ nhằm tạo điều kiện thuận lợi cho hàng hóa phương tiện được lưu thông thông tốt nhất và không xảy ra ùn tắc. Không những thế, ngân hàng Nhà nước cần xem xét cắt giảm các khoản lãi suất cơ bản. Các ngân hàng thương mại cần khoanh nợ, giãn nợ, giảm các lãi suất cho vay, mở rộng định mức cho vay, đồng thời cơ cấu lại các khoản vay đối với các doanh nghiệp trong các lĩnh vực bị tác động và ảnh hưởng mạnh từ đại dịch COVID19 như du lịch, dịch vụ, xuất khẩu nông sản, vận tải, dệt may, giày dép... Đối với các doanh nghiệp kho lạnh, mát cần được hưởng thêm các ưu đãi về giá điện dùng (hiện nay giá cao hơn giá điện sản xuất từ $25-30 \%$ ); ưu đãi thuế (như giảm thuế, không phạt chậm nộp thuế...) cho các chuỗi nhà hàng, khách sạn, cung ứng thực phẩm; giãn tiến độ nộp, giảm tiền thuê đất và mặt bằng sản xuất kinh doanh cho các doanh nghiệp chịu ảnh hưởng nhiều từ dịch (Anh, 2020).

\section{Giải pháp của doanh nghiệp}

Nhiều doanh nghiệp dịch vụ Logistics ở Việt Nam đã ứng phó với Covid-19 bằng hàng loạt các biện pháp: cắt giảm lương và/hoặc giờ làm việc của nhân viên; cắt giảm chi phí không cần thiết (44,5\% doanh nghiệp); đàm phán điều khoản thanh toán cho chi phí đầu vào và chi phí khác (38,6\% doanh nghiệp), thu hẹp quy mô sản xuất kinh doanh (37,3\% doanh nghiệp). Cần chú trọng nâng cao năng lực cạnh tranh, trình độ quản trị theo hướng đẩy mạnh chuyển đổi số để bắt kịp với xu thế ứng dụng công nghệ thông tin 
hầu hết trong các khâu của Logistics. Doanh nghiệp Logistics cần nâng cao quy trình, công nghệ, nguồn nhân lực có chuyên môn, nghiệp vụ trong lĩnh vực Logistics (Đồng, 2021). Việc tăng cường ứng dụng công nghệ với những tiến bộ của cách mạng công nghiệp lần thứ tư đang được đa số doanh nghiệp kỳ vọng sẽ làm thay đổi ngành Logistics nhiều nhất với những lợi ích hàng đầu như tăng năng suất lao động, cắt giảm chi phí, cải thiện chiến lược kinh doanh, nâng cao hiệu quả theo dõi Logistics và quản lý vòng đời sản phẩm và củng cố hệ thống vận hành....(Quỳnh, n.d.) Áp dụng giải pháp công nghệ mang lại hiệu quả cho dịch vụ Logistics và giảm đáng kể chi phí liên quan như cảng điện tử (ePort), lệnh giao hàng điện tử (eDO), số hóa chứng từ vận tải (Invoicing and Payments), đầu tư vào ứng dụng giải pháp tổng thể trong dịch vụ logistics (Saas), dữ liệu lớn (Big Data), điện toán đám mây (Cloud Computing), nhà kho thông minh (Smart Warehousing)... Đồng thời cần phải chủ động tìm kiếm, liên kết với các doanh nghiệp quốc tế có uy tín để cùng phát triển, nâng cao chất lượng dịch vụ Logistics.

Có thể thấy, đại dịch COVID-19 đã và đang có ảnh hưởng rất lớn đến nền kinh tế không chỉ ở Việt Nam mà còn ở rất nhiều nước trên thế giới. Bên cạnh đó, ngành Logistics ở Việt Nam cũng phải chịu tác động không nhỏ cho dù đó là tích cực hay tiêu cực. Đại dịch cũng là phép thử để kiểm tra khả năng của tất cả các lĩnh vực nền kinh tế. Hiện nay, dịch bệnh cơ bản đã được kiểm soát. Các doanh nghiệp ít nhiều đã có những kinh nghiệm cũng như cái nhìn bao quát về ảnh hưởng của dịch bệnh lên nền kinh tế nói chung và ngành Logistics nói riêng. Vấn đề hiện nay của doanh nghiệp chính là tìm ra các giải pháp, tháo gỡ những khó khăn để sớm phục hồi và phát triển.

\section{TÀI LIỆ THAM KHẢO}

Anh, Q. (2020). Doanh nghiệp logistics Việt ảnh huởng thế nào tù dịch Covid-19?

Vietnam Logistics Review.

BBT. (2020). Xu huớng hoạt động Logistics tại Việt Nam và thế giới trong năm 2022. Ratraco Solustions.

Bộ Công thương. (2020a). Báo cáo Logistics Việt Nam 2020: Cắt giảm chi phí Logistics. In Nhà xuất bản Công Thương, Hà Nội.

Bộ Công thương. (2020b). Báo cáo tình hình thị trường Logistics Việt Nam số tháng 
9/2020. In Nhà xuất bản Công Thương, Hà Nội.

Bộ Công thương. (2021). Báo cáo Logistics Việt Nam 2021: Phát triển nguồn nhân lực. Nhà Xuất Bản Công Thương, Hà Nội, 2013-2015.

Đồng, V. Đ. (2021). Phát triển ngành dịch vụ logistcs dưới tác động của đại dịch Covid-19. Tạp Chí Tài Chính.

Duy, M. (2020). Co hội cho vận tải đường sắt. Sài Gòn Giải Phóng.

La, V. P. et al. (2020). Policy response, social media and science journalism for the sustainability of the public health system amid the COVID-19 outbreak: The vietnam lessons. Sustainability (Switzerland), 12(7). https://doi.org/10.3390/su12072931

Ninh, V., Minh, V. T. B., Ninh, B. T., Sự, Đ. M., Việt, D. Q., \& Giao, C. T. Q. (2020). Tác động của dịch COVID-19 tới nhu cầu, kĩ năng cho người lao động và hoạt động đào tạo nguồn nhân lục Logistics cho Việt Nam.

Quỳnh, N. (n.d.). Ngành logistics đón bắt co hội nhờ áp dụng giải pháp công nghệ. 2020.

Trọng, N. Đ. (2021). Giải pháp hỗ trọ doanh nghiệp dịch vụ logistics vươt khó do ảnh huởng đại dịch Covid-19. Tạp Chí Công Thương.

Vuong, Q.H., et al. (2022). Covid-19 vaccines production and societal immunization under the serendipity-mindsponge-3D knowledge management theory and conceptual framework. Humanities \& Social Sciences Communications, 9, 22. https://www.nature.com/articles/s41599-022-01034-6

Vuong, Q. H., \& Napier, N. K. (2014). Making creativity: the value of multiple filters in the innovation process. International Journal of Transitions and Innovation Systems, 3(4), 294-327. https://doi.org/10.1504/ijtis.2014.068306 